\title{
Career choices in preventive and social medicine and other non-clinical specialties among medical students: Bangladesh perspective
}

\author{
SM Moslehuddin Ahmed ${ }^{1}$, Md. Anwarul Azim Majumdar', Rezina Karim ${ }^{3}$, Sayeeda Rahman ${ }^{4}$, Nuzhat Rahman
}

${ }^{1}$ Head and Professor, Department of Community Medicine; ${ }^{3}$ Lecturer, Department of Microbiology; Uttara Adhunik Medical College, Dhaka, Bangladesh. ${ }^{2}$ Lecturer; ${ }^{4}$ Lecturer; Department of Clinical Sciences, School of Medical Sciences, University of Bradford, West Yorkshire, Bradford, UK. ${ }^{5}$ Researcher, Department of Nutrition Sciences, University of Alabama at Birmingham, Birmingham, AL, USA.

\section{Abstract}

The main aims of the study were to identify the career choices in preventive and social medicine and non-clinical specialties along with the intended practice locations of medical students of Bangladesh. First, third and fifth year students of Bangladesh Medical College and Uttara Adhunik Medical College completed a self-reported questionnaire and were asked to choose three long-term choices from the given specialties. A small number of students opted for preventive and social medicine (3\%), medical administration and management (3\%), and basic medical science specialties. The popular choices among male and female were medical and surgical specialties (6\%). More than $67 \%$ of respondents wanted to join private services and about $90 \%$ chose major cities as practice locations. As the majority of the students intended to specialize in established clinical specialties and subsequently practice in major cities, Bangladesh will suffer a chronic shortage of health personnel in those specialties and in rural areas. Major reforms are needed in medical education and healthcare to attract and retain a health workforce in those fields and to ensure equitable and high quality healthcare for those people who have little to no access to medical services.
\end{abstract}

Keywords: Career choices, Medical students, Preventive medicine, Public health, Non-clinical, Bangladesh.

\section{Introduction}

The Dhaka Declaration on Strengthening the Health Workforce ${ }^{1}$ in the Countries of South-East Asia Region recognized the crucial importance of human resources for the effective functioning of health systems and noted unacceptable shortages, unbalanced skill mix and maldistribution in terms of geography, specialization, gender and sectors as the reasons for poor health outcomes in the Region. Studies ${ }^{2-7}$ showed that medical students are usually interested in pursuing a career as hospital-based clinical specialists and are less inclined towards preventive and social medicine, other non-clinical specialties, and work in rural areas. As a result, all these factors create an acute shortage and maldistribution of specialists in preventive and social medicine, ${ }^{8,9}$ teachers in basic medical science departments, ${ }^{10-14}$ and doctors in rural areas. ${ }^{2,5,15} \mathrm{~A}$ competent, motivated and committed health workforce forms the core of an effective and efficient health system, and healthcare reforms can only bring about intended benefits when there is an effective and optimum health workforce management in place in a country.

In Bangladesh, more than $75 \%$ of the total population lives in rural areas and only less than $40 \%$ of the population has access

\section{Practice points}

- An appropriate skill-mix and adequate distribution of health professionals is the prerequisite to providing quality healthcare.

- There are unacceptable shortages, an unbalanced skill mix, and maldistribution of the public health workforce in the SEA region.

- The present study showed that:

- Only a small number of medical students wanted to specialize in preventive and social medicine and non-clinical specialties.

- Less than one-tenth of the respondents were interested in practicing in rural areas.

- If this pattern continues, Bangladesh will suffer a chronic shortage of competent human resources in public health, basic medical sciences and management.

- Major reforms are needed in healthcare and medical education to attract and retain a health workforce in the above-mentioned fields.

Correspondence: Professor SM Moslehuddin Ahmed, Head of the Department, Department of Community Medicine, Uttara Adhunik Medical College, Dhaka-1230, Bangladesh.E-mail: ofnmosleh@yahoo.com. 
to basic healthcare. Bangladesh has already been identified as one of the countries with severe health workforce shortages and this is more prominent in rural areas. ${ }^{9,16,17}$ In recent years, the country has also been experiencing demographic and epidemiological transitions which requires a skilled workforce for the surveillance of diseases, prevention of illness and disability, promotion of health, and management and prioritization of limited health resources. More teachers are required in basic medical science subjects in health professional institutes, and para-clinical specialists (e.g. pathologists, microbiologists etc.) in upzilla (sub-district) and district level healthcare settings to ensure quality healthcare for the people. Information concerning the career choices of medical students is important in planning and implementation of the medical education and healthcare systems in a country. ${ }^{2}$ The main aims of the study were to identify the career choices in preventive and social medicine and non-clinical specialties and intended practice locations of medical students of Bangladesh.

\section{Methods}

A cross-sectional, questionnaire-based study involving medical students was conducted at two private medical colleges of Bangladesh during the period of Nov-Dec 2009. First and third year students of Uttara Adhunik Medical College (UAMC), and first, third and fifth year students of Bangladesh Medical College (BMC) anonymously completed a self-reported questionnaire which was used by Majumder et al. in their earlier studies. ${ }^{6,7}$ The questionnaire was modified based on the local context and circumstances. The details of study methodology were discussed elsewhere. $^{2}$

\section{Result}

The career choices of medical students are shown in Table 1. Of 176, 132 questionnaires were completed which produced a response rate of $75 \% ; 62$ from Uttara Adhunik Medical College and 70 from BMC.

Table 1: Career choices of medical students

\begin{tabular}{|c|c|c|c|c|c|}
\hline & Specialty/Sub-specialty* & 1st Choice & 2nd Choice & 3rd Choice & Total respondents $(\%)$ \\
\hline \multirow[t]{7}{*}{1.} & Preventive and Social Medicine & & & & $3 \%$ \\
\hline & Bio-statistics & - & 1 & - & \\
\hline & Community Medicine & - & - & 1 & \\
\hline & Epidemiology & - & - & 1 & \\
\hline & Occupational and Environmental Health & - & - & 1 & \\
\hline & Public Health & 1 & 1 & 1 & \\
\hline & Hospital Administration & 1 & & 4 & \\
\hline \multirow[t]{9}{*}{2.} & Basic Medical Sciences & & & & $6 \%$ \\
\hline & Anatomy & 1 & 1 & 3 & \\
\hline & Physiology & 1 & 1 & 2 & \\
\hline & Biochemistry & - & 1 & 2 & \\
\hline & Pharmacology & - & - & 1 & \\
\hline & Clinical Pathology & - & - & 1 & \\
\hline & Histopathology & - & 1 & 1 & \\
\hline & Microbiology & - & 1 & 3 & \\
\hline & Forensic Medicine & 1 & - & 2 & \\
\hline 3. & Medical Administration/Management & 6 & - & 7 & $3 \%$ \\
\hline 4. & General Practice & 10 & 3 & 5 & $5 \%$ \\
\hline 5. & Medicine Specialties & 58 & 53 & 49 & $40 \%$ \\
\hline 6. & Surgical Specialties & 41 & 54 & 42 & $35 \%$ \\
\hline 7. & Obstetrics and Gynecology & 12 & 15 & 6 & $8 \%$ \\
\hline
\end{tabular}

*No student opted for the following preventive and social medicine and other non-clinical specialty as their $1^{\text {st }}, 2^{\text {nd }}$, and $3^{\text {rd }}$ choices: general pathology, virology, health education, maternal and child health, medical entomology, nutrition and biochemistry, microbiology and mycology, parasitology and population dynamics. 
About $65 \%(n=86)$ of the respondents were female, and the number of students from first, third and fifth year was 32,56 and 44 respectively. Only $3 \%$ of the respondents opted for preventive and social medicine specialties, $3 \%$ for medical administration and $6 \%$ for basic medical subjects as either their 1st, 2nd or 3rd choices. It appeared that students preferred these three specialties more as the third preferences than either as the first or second. The majority of the students chose two established disciplines i.e. medicine $(40 \%)$ and surgery $(35 \%)$ as their future career. More male students selected preventive and social medicine specialties ( $5 \%$ vs. $2 \%)$ and medical administration/management $(4 \%$ vs. 3\%) than female students; however more female students chose basic medical sciences than male students ( $8 \%$ vs. $2 \%$ ). More than $67 \%$ of the respondents wanted to join private medical services and $25 \%$ in government services. About $4 \%$ of students wanted to work at rural areas and $5 \%$ in upazilla health complex. More than half of the students selected Dhaka city (64\%) and about a quarter preferred cities with medical colleges $(24 \%)$ as their place of employment.

\section{Discussion}

This is the first reported study of this kind in Bangladesh which reveals the career choices of medical students in preventive and social medicine and non-clinical specialties. The main findings of the study showed that only a small number of students were motivated to specialize in preventive and social medicine and non-clinical specialties. Less than one-tenth of the respondents were interested in practicing in rural areas including upazilla health complexes. If this pattern of career choice continues over the years, Bangladesh will suffer a chronic shortage of competent human resources in the fields of preventive and social medicine, basic medical sciences and medical administration/management. As a result, the rural areas would endure more shortages compared to the urban areas. As fewer students are interested in serving the rural people, misdistribution of doctors between urban and rural areas may constitute a major problem in future. Moreover, the loss of interest in government service is an alarming observation; a similar trend was also identified in India. ${ }^{18}$ The reason for such trend may be related to the promise of greater money and facilities in private sector as compared to government sector. ${ }^{18}$ It is optimistic to note that there is now a growing trend in Bangladesh toward preventive and social medicine and non-clinical career aspirations among medical graduates, a possible contributing factor is the conflict between increased medical student recruitment and the intensive competition for postgraduate training posts in clinical specialties.

In recent years, medical education in Bangladesh has undergone many changes and challenges ${ }^{19,20}$-a communityoriented and competency-based medical curriculum was implemented since 1988 to produce need-based doctors for the community. The findings of this study indicate that the goals for undergraduate and postgraduate medical education and training should have to be redefined; incentives/rewards and career paths need to be addressed, and professional bodies and associations should take leading roles to promote their respective specialties. Further long-term follow-up studies should be conducted to identify the career choice of medical students in preventive and social medicine and other non-clinical specialists.

\section{Conclusion}

An effective health system depends on appropriate skillmix and adequate distribution of health professionals in all specialties and geographical locations. To achieve this, national policies need to be developed to enhance the availability of an adequate number of health workers in preventive and social medicine and other non-clinical settings. Major reforms are needed in healthcare and medical education to attract and retain health workforce in those fields, and to ensure equitable and quality healthcare for the underserved and unserved population of the country.

\section{Acknowledgment}

The authors would like to thank the teachers and students of BMC and UAMC who helped and participated in the study.

\section{References}

1. World Health Organization, South East Asia Region. Health Ministers of WHO's South-East Asia Region call for consolidation of efforts to improve the health of their countries (press release). http:// www.searo.who.int/en/Section316/Section503/ Section2141_12044.htm (accessed 30 Nov 2011)

2. Ahmed SMM, Majumdar MAA, Karim R, Rahman S, Rahman N. Career choices among medical students in Bangladesh. Adv Med Educ Pract 2011;2:518.

3. Ahmed Z, Ja'afar R. Career preferences of male and female medical students in Malaysia. Med J Malaysia 1997;52:76-81.

4. Huda N, Yousuf S. Career preference of final year medical students of Ziauddin Medical University. Educ Health 2006;19:345-53.

5. Karalliedde LD, Senanayake N, Aluwihare AP. Career preferences of the 1984 medical graduates of Sri Lanka. Med Educ 1986;20:64-8.

6. Majumder MAA, Rahim AFA, Rogayah J, Sadiq MAH, Alwi MNM, WHW Hitam, Abdullah M. Career choices of the 2003 medical graduates of Universiti Sains Malaysia. Poster presentation in the 8th National Conference on Medical Sciences, Universiti Sains Malaysia, 8-9 May, 2003, Kelantan, Malaysia. Malaysian JMed Sci 2003;10:164.

7. Majumder MAA, Rahim AFA, Rogayah J, Sadiq MAH, Alwi MNM, WHW Hitam, Abdullah M. Specialty choices, predictive factors and intentions to practice in Malaysia: a survey among the recent 
medical graduates of Universiti Sains Malaysia (USM). Conference booklet of 4th Asia-Pacific Conference on Science and Technology, 23-25 Sept, 2003, Kuala Lumpur, Malaysia.

8. Kawnine N, Gunness L, Killingsworth J, HedrickWong Y, Gruen R, Normand C, Anwar R. Economic aspects of human resource development in health \& family in Bangladesh: Costs of education and training of health workers in Bangladesh. Health Economics Unit, Ministry of Health and Family Welfare, Government of Bangladesh. Dhaka: MOH\&FW, 1998.

9. Mahmood SS, Iqbal M, Hanifi SMA, Wahed T, Bhuiya A. Rare 'Village Doctors' in Bangladesh a curse or a blessing? BMC Int Health Hum Rights 2010, 10: 18.

10. Amin Z, Merrylees N, HanifA, Talukder MH. Medical education in Bangladesh. Med Teach 2008;30:243-7.

11. Ananthakrishnan N. Acute shortage of teachers in medical colleges: Existing problems and possible solutions. NMJI2007; 20:1-8.

12. Chakraborty SK, Hakim M, Banu LA, Yousuf BMA, Ali MS, Shamim KM. Anatomy as an Emerging Science and Career Option in View of Medical Students in Bangladesh. Bangladesh J Anat 2010;8:2833.

13. Dixit H, Marahatta SB. Medical education and training in Nepal: SWOT analysis. Kathmandu University Med
J2008;6:412-20.

14. Shah Navas P. Medical Education in India at Crossroads. Kerala Med J2011:1:36-9.

15. Jaafar R, Ahmed Z. Career preferences of medical students in a community-oriented medical school. Ann Network Community Oriented Educ 1993;6:301-10.

16. Ahmed SM, Hossain MA, Chowdhury AMR, Bhuiya AU. The health workforce crisis in Bangladesh: shortage, inappropriate skill-mix and inequitable distribution. Hum Resour Health 2011;9:3.

17. Al-Kabir A, Khan FR, Chowdhury JH. An incentive package for deployment and retention of Public-sector health workers in hard to reach areas of Bangladesh. 4th AAAH Conference, 23-25 November 2009, Hanoi, Vietnam.

18. Lal P, Malhotra C, Nath A, Malhotra R, Ingle GK. Career aspirations and apprehensions regarding medical education among first year medical students in Delhi. Indian J Community Med 2007;32:217-8.

19. Majumder MAA. A review of the undergraduate medical curriculum in Bangladesh. Bangladesh Med J 2002;31:47-9.

20. Majumder MAA. Medical education in Bangladesh: Past successes, future challenges. Bangladesh Med J 2003;32:37-9. 